\title{
Релевантность понятий «гештальт», «фигура», «фон», «фокус» для анализа концептуальной области «кажимости»
}

\author{
Е. В. ЧЕРНЦОВА \\ Кафедра русского языка, Харьковский национальный университет \\ имени В. Н. Каразина, майдан Свободи, 4, UA-61022 Харків \\ E-mail: e.v.cherntsova@gmail.com
}

(Received: 22 January 2019; accepted: 9 June 2019)

Цель статьи состоит в том, чтобы предложить метакогнитивную репрезентацию гештальта концептуальной области «кажимости»; в терминах «фигура», «фон», «фокус» схематично показать корреляцию между концептуальным уровнем и уровнем языковой семантики. Выделение двух названных уровней производится в исследовательских целях и является условным.

Когнитивная теория рассматривает то, как человек осмысливает мир, а языковые правила в большей или меньшей степени считаются частью нашего когнитивного аппарата. «Если считать, что язык отражает тот способ, с помощью которого человек представляет себе мир, то необходима теория языка, учитывающая человеческий опыт. Именно такое требование предъявляется к основанной на опыте лингвистике: широкий круг эмпирических факторов - восприятие, мышление, устройство человеческого тела, эмоции, память, социальные структуры, сенсорно-моторные и познавательные процессы и т. п. - в значительной степени, если не целиком, обусловливает универсальные структурные характеристики языка» (ЛАкофФ 1981: 350). Западные исследователи (Дж. Лакофф, У. Л. Чейф, Ч. Филлмор, Л. Талми) и российские лингвисты (В. З. Демьянков, Е. С. Кубрякова, О. К. Ирисханова) приходят к аргументированным выводам о том, что разные когнитивные системы - зрение и язык - проявляют сходство общих принципов организации разной информации (ЛАКОФФ 1981, ЧЕЙФ 1983, ФилЛМОР 1988, ТАЛми 2006, ДЕМьянКОв 1992, КуБРяКОвА 2012, ИРИСХАНОва 2014).

Термины гештальтпсихологии «гештальт», «фигура», «фон» используются в когнитивной лингвистике и обозначают когнитивную и психическую структуру («гештальт»), которая характеризует человеческое восприятие и интерпретацию действительности и не сводится к совокупности ее частей (КуьряковА и др. 1997: 185-186). Понятие «гештальт» предполагает способность человеческой психики организовывать опыт в целостные в функциональном отношении структуры, образы, формы. Гештальты являются одновременно целостными и анализируемыми. Они состоят из частей, но не сво- 
димы к совокупности этих частей. Части гештальта связаны внутренними отношениями, при этом способ соотношения частей в рамках гештальта входит в содержание самого гештальта. Гештальты не образуются в результате простого суммирования признаков объектов, а воспринимаются как «фигура» на «фоне», при этом в структуре гештальта «фигура» задается «фоном».

В теории гештальтов различие «фигура - фон» рассматривается как наиболее простая форма перцептуальной организации. Различие «фигуры» и «фона» объясняется их разными перцептуальными свойствами (ДЕмьянков 1992: 65). Суть этого различия заключается в следующем: при восприятии любого дифференцированного поля «фигура» представляется лежащей впереди или расположенной на «фоне». «Фон» воспринимается как непрерывный континуум за (или под) «фигурой». Выделение «фигуры» на «фоне» всего остального считается автоматическим и обязательным.

Понятия «фигуры» и «фона» принадлежат к наиболее значимым для когнитивных описаний, так как в них наиболее явно отражается одна из центральных идей когнитивной лингвистики: «язык представляет собой одну из сторон познавательных процессов, и, следовательно, принципы построения и функционирования языковых единиц и выражений обязательно имеют аналог в других нелингвистических проявлениях познания - в том числе в зрительной перцепции и ориентации в пространстве» (ИРисХАНОВА 2014: 33). Так, когнитивистский подход к исследованию дискурса и текста учитывает обязательность различения «фигуры» и «фона» при любом восприятии. Считается, что языковые структуры кодируют и направляют распределение внимания между «фигурой» и «фоном», поэтому понятия «фигуры» и «фона» используются при изучении синтаксических явлений, темо-рематической организации предложения, роли порядка слов, акцентного выделения и др. В литературоведческих исследованиях систематические различия между выделенными и фоновыми частями художественного текста интерпретируются как языковой аналог перцептуального различия «фигуры» и «фона». Исследователи считают, что именно это и позволяет читателям интерпретировать некоторые части текста как более заметные, значимые/ релевантные, т. е. выступающие как «фигура» по отношению к «фону»- всему остальному тексту (КуБРяковА и др. 1997: 186).

Проводимое нами исследование языковой семантики в когнитивистской системе понятий базируется на методологически важном тезисе о том, что вербальная деятельность во многом следует законам перцепции; визуальная информация хранится в памяти, повторяя основные контуры расположения объектов в пространстве. Термины «фигура», «фон», «фокус» подчеркивают тот факт, что характер выделяемой сущности во многом зависит от невыделенной, фоновой структуры знаний, в которую эта сущность погружена (ИрисхановА 2014: 24-63).

Метакогнитивная репрезентация гештальта концептуальной области «кажимости» строится с опорой на инферентные выводы, полученные в результате когнитивно-дискурсивного анализа контекстов функционирования 
многозначных глагольных предикатов казаться, показаться. В духе когнитивистского понимания термина «контекст» был проанализирован значительный языковой материал, взятый из Национального корпуса русского языка. Дифференциация контекстных значений многозначных глагольных предикатов казаться, показаться проводилась в соответствии со следующими параметрами: первый параметр - «дискурсивный тип контекста» - позволяет осмыслить специфику контекстов обыденного, публицистического, научного, художественного дискурса. Основные результаты анализа семантики контекстов разного дискурсивного типа представлены в ранее опубликованных нами статьях (ЧЕРнцОвА 2013, ЧЕРнцОВА 2016).

Второй параметр - «коммуникативный тип контекста» - включает показатель диалогичности/монологичности высказывания (на этом основании различаются «Я»-, «ТЫ»-, «ОН»-контексты); а также характеристику коммуникативной интенции, коммуникативной стратегии говорящего. Учет коммуникативных параметров позволил осмыслить коммуникативные установки говорящего в корреляции с когнитивными основами его речи. В результате были выявлены когнитивные признаки контекстов разного типа, а именно: репродуктивного, информативного, «Я»-контекста воспоминания и эпистемического контекста.

На базе проведенного когнитивно-дискурсивного анализа языкового материала был реконструирован гештальт-сценарий концептуальной области «кажимости». Анализ языкового материала показывает, что все рассмотренные контексты с глагольными предикатами казаться, показаться строятся по правилу этого гештальт-сценария. Интересующий нас гештальт концептуальной области «кажимости» отражает опыт носителей языка: гештальтсценарий связан с онтологией процесса восприятия.

Так, контекст с глагольным предикатом показаться воссоздает прагматическую ситуацию актуального наблюдения говорящим некоторого объекта, который становится предметом обсуждения в обыденном диалоге, ср.:

(1) - Посмотри: только что из-за туч показалось солнце.

Этот тип контекста называем репродуктивным. Для нас принципиально важно, что репродуктивный контекст строится в соответствии с общими принципами зрительного восприятия, отражает прототипическую ситуацию восприятия. В репродуктивном контексте конструируется пространственная перспектива - позиция наблюдателя, т. е. местоположение, из которого субъект наблюдает за происходящим. Субъект-наблюдатель локализован в пространстве «возможного» мира, как правило, находится на значительном расстоянии от наблюдаемого объекта. Наблюдатель занимает синхронную с временем описываемого события позицию. В контексте с предикатом показаться концептуализируется первая зрительная фиксация наблюдаемого объекта («фигура») на каком-то «фоне». В фокусе внимания говорящего находится объект, названный именем существительным в именительном падеже (солнце). В контексте содержится указание на «фон» - это синтаксема из-за туч. 
В качестве «фона» выступают другие объекты действительного мира, которые ранее заслоняли наблюдаемый объект, делали его не видимым для наблюдателя, ср.:

(2) Из-за угла показался прохожий.

(3) Из-за поворота показалась машина.

(4) В проеме освещенного окна показался силуэт человека.

(5) Послышался топот копыт, и стройный всадник на красивом гнедом коне показался на улице (И. С. Тургенев: Дворянское гнездо).

Когнитивные признаки репродуктивного контекста с предикатом показаться можно зафиксировать в следующем метавысказывании: «говорящий находится в локусе происходящего события; говорящий первый раз замечает некоторый объект на фоне чего-то другого и привлекает внимание собеседника к наблюдаемом объекту».

Гештальт интересующей нас концептуальной области строится так: субъект-наблюдатель первый раз замечает объект, находясь на значительном расстоянии от него. Гештальт-сценарий также фиксирует принципиальную возможность изменения первого впечатления субъекта: например, если наблюдатель приближается к заинтересовавшему его объекту, то получает возможность лучше рассмотреть объект, сформировать более полное представление о нем. С позиции этого, более полного представления / знания субъект получает возможность осмыслить первичное впечатление как соответствую щее или не соответствующее тому, что имеется в действительности, оценить первое впечатление как «истинное» или «обманчивое». Это вывод базируется на анализе семантики контекстов художественного дискурса, ср.:

(6) Я вглядывался в рытвины Столовой горы, промытые протоками и образующие так называемые «ножки стола». На этом расстоянии то, что издали казалось мхом, травкой, явилось целыми лесами кустов и деревьев. Вся гора, взятая нераздельно, кажется какой-то мрачной, мертвой, безмолвной массой, а между тем там много жизни: на подошву ее лезут фермы и сады, в лесах кишат змеи, бегают шакалы и дикие козы (И. А. Гончаров: Фрегат «Паллада»).

(7) С бешено несущегося поезда казалось, что возы стоят не двигаясь, а лошади подымают и опускают ноги на одном месте (Б. Л. Пастернак: Доктор Живаго).

(8) Не верилось, что ее [волну] сдерживает редкая цепь неуклюжих машин, казавшихся отсюда совсем маленькими (А. и Б. Стругацкие: Далекая Радуга).

Когнитивный гештальт-сценарий представляет восприятие как динамичный процесс, состоящий из этапов. Первый этап - перцептивное восприятие, второй этап - ментальное осмысление перцептивных данных. Каждый из двух названных этапов восприятия получает репрезентацию в контексте репродуктивного или информативного типа. Ментальное осмысление перцептивных данных концептуализируется в контексте, который мы называем 
информативным. Информативный «Я»-контекст воссоздает другую прагматическую ситуацию: «говорящий не находится в локусе описываемого им события; говорящий интерпретирует ситуацию, оценивает ее с позиции предварительных знаний», ср.:

(9) Мне эта точка зрения кажется странной.

(10) Мне кажется, всех надо судить одной меркой.

(11) Мне кажется, что мама ушла из дома не только в знак протеста, а потому еще, что не могла вынести взгляда Саши, он был ей укором (А. Н. Рыбаков: Тяжелый песок).

Среди задач когнитивно-дискурсивного исследования нет традиционной задачи классифицировать языковой материал, однако релевантна исследовательская процедура дифференциации контекстных значений избранных слов. Исследовательская процедура дифференциации контекстных значений наталкивается на сопротивление материала: языковая семантика континуальна, в каждом значении «просвечивает» концептуальное целое. Целостность концептуальной семантики проявляется в том, что информативное значение сохраняет связь с репродуктивным, ср.:

(12) Из Украины мне казалось, что Австралия так далеко, но я прилетела в Мельбурн всего за 24 часа.

(13) И если мы хотим, чтобы наши действия не казались нелепыми в свете этого закона, мы должны следовать ему (А. и Б. Стругацкие: Далекая Радуга).

Интерпретация, умозаключение, вывод восходят к акту перцепции, имеют эмпирическую основу. Это показывают контексты, в которых предикаты, маркируя процесс интерпретации, осмысления чего-то, тем не менее, сочетаются с распространителями с первого взгляда кажется/может показаться; на первый взгляд кажется/могло показаться, ср.:

(14) На первый взгляд статья кажется простой и понятной.

(15) С первого взгляда она кажется вполне счастливой.

Подобные контексты актуализируют связь репродуктивного и информативного значений - «интерпретация говорящего сложилась как результат наблюдения объекта, на базе зрительных образов, у которых могут быть реальные прототипы».

Этап ментального осмысления перцептивных данных получает в дискурсивном контексте когнитивный статус «знание» субъекта. «Знание» же формирует пресуппозитивную базу для рефлексивного акта субъекта, ср.:

(16) За нас плотно взялись кредиторы, и казалось, что ситуация начала налаживаться. Но только показалось.

(17) Сначала казалось, что, расшифровав полную генетическую информацию геномной ДНК, мы сможем управлять процессами, происходящими в клетке (В. Л. Карпов: ДНК, хроматин, гистоновый код. // Вестник РАН, 2003). 
Ментальная модусная рамка мне кажется/мне показалось имплицирует/ эксплицирует опыт рефлектирующего субъекта - «говорящий знает о том, что первое впечатление/мнение может быть ошибочным, что впоследствии оно может смениться другим представлением/знанием». В разных контекстах этот смысл предстает по-разному: он то эксплицируется, то остается имплицитным. Ср. диалог:

(18) - Мне кажется, он порядочный человек.

- Тебе это показалось!

В форме настоящего времени имперфективного предиката мне кажется концептуализируется длительность когнитивного процесса говорящего, синергетически связанного с будущзим рефлексивным актом. В связи с этим в контексте с имперфективным предикатом имплицируется рефлексивный акт как потенциально возможный (говоря когнитивистским языком, рефлексивный акт остается дефокусированным). В форме же прошедшего времени перфективного предиката мне показалось концептуализируется другое временное значение - взгляд назад, в ретроспективу. А в связи с этим перфективный предикат эксплищирует рефлексивный акт субъекта как уже произошедший (говоря когнитивистским языком, рефлексия выдвигается на первый когнитивный план, попадает в фокус внимания). Со значением прошедшего времени связано значение мгновенности, «летучести» мысли, быстрой сменяемости мыслей. Это формирует значение перфективного предиката, связанное с большей «субъективностью» интерпретации говорящего, чем у имперфективного, ср.:

(19) - И вот покажись мне, что девица расположена ко мне сердечно, - разгорелось мое сердце при такой мечте (Ф. М. Достоевский: Братья Карамазовы).

(20) - Послушать тебя, так покажется, что мы не на острове сидим, а где-нибудь близ железнодорожного узла Липки (А. Б. Чаковский: У нас уже утро).

Реконструируемая нами концептуальная область кажимости (гештальтсценарий) может быть описана как неопределенная, размытая, континуальная и диффузная. В отличие от концептуальной, языковая семантика предстает как фрагмент концептуальной области, как будто бы выхваченный когнитивным фокусом внимания. Когнитивный фокус внимания наводится контекстом: говорящий выбирает пропозициональную структуру, порядок слов, делает нужные акценты и др.

Анализ в терминах «фигура - фон» позволяет схематично показать корреляцию между концептуальным уровнем (гештальт-сценарий) и уровнем языковой семантики (семантика контекста). Реконструированный нами гештальт концептуальной области «кажимости» выполняет роль «фона», на котором выделяется «фигура» - семантика контекста.

В свою очередь, в соответствии с правилом выделения «фигуры» на «фоне», в каждом контексте «высвечивается» свое (более конкретное) значе- 
ние слова. Чтобы эксплицировать роль игры «фокуса» в создании значения слова («фигура») в контексте («фон»), сравним разные значения полисемантичного глагольного предиката казаться в корреляции с семантикой разных типов контекста - репродуктивного, информативного, контекста воспоминания и эпистемического контекста.

Как уже отмечалось, семантика репродуктивного контекста иконически отражает ситуацию восприятия. Семантика контекста выполняет роль «фона», на котором «высвечивается» «фигура»- значение «первое зрительное впечатление от увиденного», ср.:

(21) Образовавшаяся на дороге пробка кажется огромной.

Пропозициональная структура что мне кажется каким формирует два фокуса внимания - тематический и рематический. В тематическом фокусе находится наблюдаемая говорящим ситуация действительного мира - образовавщаяся на дороге пробка. В реме - первое зрительное впечатление говорящего, оценка наблюдаемой ситуации. Коммуникативная интенция говорящего может быть определена как указание на замеченный объект или ситуацию и сообщение о первом впечатлении / мнении.

Если мы сравним репродуктивный контекст с информативным, то обнаружим, что когнитивный фокус перемещается с наблюдаемого объекта на содержание мыслей говорящего-наблюдателя («фигура»):

(22) Перспектива застрять в пробке на целый час кажется ужасной.

Здесь тематический фокус «наводится» на компонент «содержание мыслительной деятельности говорящего», а рематический - на оценку содержания собственной мысли.

Третий тип контекста - «Я»-контекст воспоминания - характеризуется следующими когнитивными признаками: «говорящий рассказывает о прошлой ситуации, в которой принимал непосредственное участие; говорящий обладает знаниями о том, как на самом деле происходило описываемое событие». Ретроспективный взгляд на событие, базирующийся на знаниях, дает рассказчику преимущество по сравнению с актуальным наблюдением. В «Я»-контексте воспоминания с предикатом (мне казалось) имплицируется сложная субъектная структура: субъектом-экспериенцером выступает говорящий как участник прошлой ситуации («Я» в прошлом), субъектом же знания и субъектом речи является говорящий - «Я» в настоящем. В языковом материале представлены две семантические разновидности «Я»-контекста воспоминания. Сравним их:

(23) Прошлой весной мне какое-то время казалось, что это дерево засохло; но ровно через год оно выпустило зеленую веточку.

(24) Прошлой весной мне казалось, что это дерево засохло. Позже я убедился, что был прав. 
Во фрагменте (23) у предиката возникает значение «говорящий осознает, что его первое впечатление было ошибочным». Как представляется, данное контекстное значение («фигура») обусловливается содержанием широкого контекста («фона»). Во втором случае (24) смысл «говорящий в прошлом ошибался» остается дефокусированным, «затемненным», так как в содержании широкого контекста сообщается о противоположном положении дел.

Четвертый тип контекста - эпистемический - представлен в материале научного дискурса. Так, в статье «Иллюзии восприятия» из краткого психологического словаря приводятся рисунки двухмерных контурных изображений, описываются иллюзорные зрительные эффекты, возникающие у реципиента, ср.:

(25) Две центральные окружности кажутся различными, хотя в действительности они одинаковы.

(26) Из двух равных по длине отрезков вертикальный кажется больше (горизонтально-вертикальная иллюзия).

(27) Два вертикальных отрезка равны, но правый кажется больше (перспективная иллюзия).

(28) Отрезки одной косой линии кажутся сдвинутыми относительно друг друга.

В рассматриваемых контекстах концептуализируются научные знания о том, что в момент зрительного восприятия особых геометрических изображений у реципиента возникают оптико-геометрические иллюзии. Коммуникативная стратегия автора научного дискурса обусловлена установкой объяснить читателю причины и сам механизм возникновения иллюзорных эффектов. Зрительные иллюзорные эффекты возникают из-за особого взаимного расположения геометрических фигур (например, горизонтальный и вертикальный отрезки), из-за наличия других фигур (окружности, прямоугольники).

Общий ход наших рассуждений таков: концептуализированное в контекстах научное знание об иллюзорных эффектах, говоря когнитивистским языком, формирует «фон». Если контекстуальный «фон» утверждает, что «из-за особого взаимного расположения геометрических фигур на картинке, у реципиента искажается восприятие», то, в соответствии с обыденной логикой, в когнитивном фокусе внимания оказывается смысл («фигура») - «зрительные впечатления такого субъекта иллюзорны, им нельзя доверять».

Контексты эпистемического типа показывают, что ментальный модус предполагает отрыв от акта перцепции, эпистемическая информация может противоречить перцептивным данным: «не всегда зрительные впечатления человека могут быть надежным основанием для выводного знания». В контекстах эпистемического типа репродуктивное значение глагольного предиката казаться полностью не исчезает («субъект-экспериенцер смотрит, видит объекты, но видит искаженно»), оно как будто бы отодвигается на второй когнитивный план, дефокусируется. В таком контексте на первый когнитивный план выдвигается эпистемическое значение, оно доминирует над репродуктивным. 
Таким образом, метакогнитивная репрезентация гештальта концептуальной области «кажимости» включает концептуализированный в семантике контекстов опыт носителей языка. Этот опыт можно описать следующими метавысказываниями. Говорящий знает, что можно не разглядеть наблюдаемый объект как следует, если находиться на большом расстоянии от него, т. е. первое впечатление от увиденного может оказаться ошибочным. Говорящий также знает, что впоследствии можно подойти ближе к наблюдаемому объекту и рассмотреть его, т. е. перепроверить результаты перцепции эмпирически. Это позволяет сформировать более полное представление (знание) об объекте. Впоследствии - с позиции полученного представления / знания говорящий рефлектирует над своим первым зрительным впечатлением, оценивает его как истинное или ошибочное. Говорящий также знает, что существуют особые обстоятельства, под действием которых искажаются зрительные образы объектов действительного мира и у реципиента возникают зрительные иллюзии.

Смысловая целостность реконструированного гештальт-сценария имплицирована во всех контекстах употребления глагольных слов казаться, nоказаться, однако в разных дискурсивных контекстах в качестве «фона» выделяются разные фрагменты гештальт-сценария, а на том или ином конкретном «фоне» выделяется более мелкий фрагмент в качестве доминирующей «фигуры» гештальта. Так схематично можно объяснить порождение разных контекстных значений полисемантичного слова. Термины «фигура - фон» эксплицируют обусловленность выделяемого содержанием невыделяемого. Игры «фокуса» внимания связаны с разными коммуникативными интенциями говорящего, разными коммуникативными стратегиями и более общим характером осуществляемой им когнитивной и дискурсивной деятельности.

\section{Литература}

ДЕмьянков 1992 = ДЕмьянков В. З. Когнитивизм, когниция, язык и лингвистическая теория. В кн.: Язык и структуры представления знаний. Москва, 1992. 39-77.

ИРИСХАНОВА 2014 = ИРИСХАНОВА О. К. Игры фокуса в языке. Семантика, синтаксис и прагматика дефокусирования. Москва, 2014.

КуБРякОВА 2012 = КУБРякОВА Е. С. В поисках сущңности языка. Когнитивные исследования. Москва, 2012.

КуБРЯКОВА и др. 1997 = КуБРЯКОВА Е. С., ДЕМьЯНКОВ В. З., ПАНКРАЦ Ю. Г., ЛузИНА Л. Г. Краткий словарь когнитивных терминов. Москва, 1997.

ЛАКОФФ 1981 = ЛАКОФФ Дж. Лингвистические гештальты. Новое в зарубежной лингвистике. Вып. 10. Лингвистическая семантика. Москва, 1981. 350-368.

ТАЛми 2006 = ТАЛми Л. Феномены внимания. Вопросы когнитивной лингвистики 2006/2: 23-44.

ФиллмоР 1988 = ФиллмоР Ч. Фреймы и семантика понимания. Новое в зарубежной лингвистике. Вып. 23. Когнитивные аспекты языка. Москва, 1988. 52-92.

ЧЕйФ 1983 = ЧЕйФ У. Память и вербализация прошлого опыта. Новое в зарубежной лингвистике. Вып. 12. Прикладная лингвистика. Москва, 1983. 35-73. 
ЧЕРНЦОВА 2013 = ЧЕРнцОВА Е. В. Дискурсивные модификации субъектных значений предикатов казаться, показаться. Наукові записки Луганського національного університету. Серія «Філологічні науки». № 2. Дискурсологія: мова, культура, суспільство. Луганськ, 2013. 45-61.

ЧЕРНЦОВА 2016 = ЧЕРнцОВА Е. В. Художественная нарративная стратегия и когнитивная семантика слова (на материале глагольных предикатов казаться, показаться). Вісник Харківського національного університету. Серія «Філологія». Вип. 75. Харків, 2016. 6-11.

\section{Olena Vadymivna Cherntsova \\ Russian Language Department, V. N. Karazin Kharkiv National University \\ The Relevance of the Concepts gestalt, figure, background, and focus for the Conceptual Framework Analysis of кажимость}

The paper suggests the metacognitive representation of the conceptual framework of $\kappa a-$ жимость gestalt. The metacognitive representation is based on the inferential conclusions obtained by cognitive-discursive analysis of the functioning contexts of polysemous verbal predicates казаться, показаться. The Gestalt script includes native speakers' experience conceptualized in the semantics of contexts. This experience can be presented by the following meta-utterances: The speaker knows that it is not possible to see an object being observed properly from afar, i.e. the first impression of it could turn out to be mistaken. The speaker also knows that it is possible to come closer to the object afterwards and observe it, i.e. to re-verify the results of perception empirically. This allows them to form a more complete idea/knowledge about the object. Subsequently, the speaker reflects on his first visual impression based on the received idea/knowledge, evaluates it as "true" or "false". In addition, the speaker is aware that there are particular circumstances under which effect the visual images of objects in the real world are distorted and the recipient receives visual illusions.

In the paper, a cognitive Gestalt script was formed. Based on it, all contexts with the words казаться, показаться are built. Due to the dialectical combination of perceptual and epistemic modes, a single/unified Gestalt script consists of two parts. On the one hand, there is supposed to be a subject-experiencer as well as his perceptual act, the object he observes, the first, potentially erroneous / distorted image of the object. There should also be a potential opportunity to implement an act of reflexive verification of the first impression and establish the truth. On the other hand, there is supposed to be the subject as a bearer of knowledge, his knowledge of the distorted character of the subject-experiencer's perception as well as his knowledge of the inconsistency between the subject-experiencer's first impression and what exists in reality. In addition, there should be implicit/explicit awareness of the reasons that led to the distortion of the perception results.

The author demonstrates the integrity of the conceptual semantics of the Gestalt script. The correlation between the conceptual level and the level of language semantics is shown in a sketchy way in terms of figure, background, and focus. The author also describes focus shifts which underlie the construction of different contexts - background and figure.

Keywords: cognitive semantics, conceptualization, conceptual framework, gestalt, figure, background, focus, metacognitive representation, proposition 